\title{
Determinants of social participation of visually impaired older adults
}

\author{
Manna A. Alma • Sijrike F. Van der Mei • \\ Johan W. Groothoff - Theo P. B. M. Suurmeijer
}

Accepted: 11 May 2011/Published online: 2 June 2011

(c) The Author(s) 2011. This article is published with open access at Springerlink.com

\begin{abstract}
Purpose To assess determinants of social participation among visually impaired older adults.

Methods This cross-sectional study included visually impaired persons ( $\geq 55$ years; $n=173$ ) who were referred to a low-vision rehabilitation center. Determinants (i.e., sociodemographic, physical, social and psychological factors, and personal values) of participation were identified in four domains of participation: (1) domestic life; (2) interpersonal interactions and relationships; (3) major life areas; and (4) community, social, and civic life. Study participants completed telephone interviews.

Results Age, physical fitness, and helplessness were determinants of participation in domestic life. Social network size was associated with participation in major life areas. The personal value attached to participation (i.e., perceived importance) was a determinant of participation in interpersonal interactions and relationships, major life areas, and community, social and civic life. Vision-related characteristics (i.e., self-perceived vision and degree of visual impairment) were not associated with participation. Conclusions Across the participation domains, perceived importance is a major determinant of social participation among visually impaired older adults. Physical health along with social and psychological status, also affect participation. Knowing how participation is determined can be used to develop rehabilitation interventions to enhance participation of visually impaired older adults.
\end{abstract}

M. A. Alma ( $\varangle)$. S. F. Van der Mei · J. W. Groothoff .

T. P. B. M. Suurmeijer

Department of Health Sciences, University Medical Center

Groningen, University of Groningen, PO Box 196,

9700 AD Groningen, The Netherlands

e-mail: m.a.alma@med.umcg.nl
Keywords Social participation - Elderly · Low vision · Determinants · Physical health status · Psychosocial factors

\begin{tabular}{|c|c|}
\hline \multicolumn{2}{|c|}{ Abbreviations } \\
\hline $\mathrm{CI}$ & Confidence interval \\
\hline GFE & Groningen fitness test for the elderly \\
\hline ICF & $\begin{array}{l}\text { International classification of functioning, } \\
\text { disability, and health }\end{array}$ \\
\hline ICQ & Illness cognition questionnaire \\
\hline ISCED & $\begin{array}{l}\text { International standard classification of } \\
\text { education }\end{array}$ \\
\hline MFI & Multidimensional fatigue inventory \\
\hline OR & Odds ratio \\
\hline PART-S & $\begin{array}{l}\text { Participation assessment with recombined } \\
\text { tools-satisfaction }\end{array}$ \\
\hline QoL & Quality of life \\
\hline SMAS-30 & Self-management ability scale \\
\hline SD & Standard deviation \\
\hline VFQ-25 & Visual functioning questionnaire \\
\hline VI & Visual impairment \\
\hline VODS & Visus Oculi Dextri Sinistri \\
\hline WHO & World health organization \\
\hline
\end{tabular}

\section{Introduction}

Due to aging of the population and the exponential increase in vision loss with increasing age, the number of older adults with a visual impairment is expected to increase [1, 2]. Along with the general consequences of aging, these older adults will experience additional restrictions due to vision loss, and as such, they will be doubly burdened [3] Vision loss may lead not only to limitations in performing activities [4-12], but also to a loss of these activities [13, 
14], and consequently poses a severe threat to the independence of older adults with a visual impairment.

The concept of participation has become more important since the development of the International Classification of Functioning, Disability, and Health (ICF) by the World Health Organization (WHO) [15]. According to the ICF, participation is defined as "involvement in life situations". The ICF offers a comprehensive model of objective disability outcomes but does not address the subjective perceptions of people with disabilities such as quality of life (QoL) [16]. The WHO, however, does recognize the importance of the QoL concept, as evidenced by their definition of QoL: "the individuals' perception of their position in life in the context of the culture and the value system in which they live and in relation to their goals, expectations, standards and concerns" [17]. With respect to the relationship between participation and QoL, and the available options to include the concept of QoL in the ICF, it is recommended to add QoL as a separate domain to the right of participation [16]. The extent of QoL can be regarded as the ultimate outcome of the disability process [16].

Studies in older adults with and without disabilities showed that participation contributes to QoL [18-20] and is a means of experiencing one's social connection with other people and communities [21]. Participation is also associated with a reduced risk of cognitive [22] and functional decline [23, 24]. Therefore, it is important to understand which factors influence the level and the extent of an individual's participation. According to the ICF framework, there is a dynamic interaction between the health condition, contextual factors, such as personal and environmental factors, and participation [15].

With aging, the presence of limitations in physical functioning and participation restrictions increases [25]. Previous research revealed several factors that are associated with participation and participation restrictions. The younger generation of older adults, for example, perceive less restrictions in interpersonal interactions [25] and are more likely to participate in social and leisure activities $[26,27]$. Other sociodemographic factors, such as income [28] and educational level [29], are associated with participation in voluntary work, and cultural and recreational activities. Older adults with a good health status [30] and those who are physically fit [31] perceive less restrictions in daily activities and are more likely to participate in social activities. Social support from family and friends is a facilitator of participation in society as well [32]. Psychological factors such as emotional distress [33] and reduced self-efficacy $[34,35]$ are barriers for participation in outdoor activities, social relationships, and work. In addition to these factors, personal expectancies and personal values concerning participation may determine behavior of older adults [36]. Based on this literature, it can be concluded that sociodemographic factors, physical health status, social and psychological status, and personal values affect participation.

Although participation has been studied among older adults in general [25-27, 29-32], to our knowledge, only a few studies investigated participation of visually impaired older adults. The results of these studies indicate that reduced distance vision restricts participation in social interactions, daily activities (including household activities), leisure activities, and work [11, 37, 38]. The perceived quality of distance vision as well as the presence of cardiac disease, and the use of special equipment (e.g., cane, pill dispenser) are associated with reduced participation in self-care, household activities, physical activities, and limitations in mobility [37]. In addition, the physical and mental health of visually impaired older adults affect restrictions in participation [11]. Apart from these studies, there is little available information about the determinants of participation of visually impaired older adults.

The present study aims to investigate factors that influence the level of participation of visually impaired older adults. For this purpose, the impact of various factors will be examined according to the biopsychosocial model. Based on the literature, we expect that sociodemographic variables, physical health status, social status, and psychological status will affect participation. In addition, the effect of the personal values that visually impaired older adults attach to participation will be examined.

\section{Methods}

\section{Study population}

A sample of 350 persons was drawn out of the 786 newly registered visually impaired older clients of Royal Dutch Visio (North Netherlands), a low-vision rehabilitation provider, between July 1, 2006, and June 30, 2007. The main inclusion criteria were being aged $\geq 55$ years and being referred to a low-vision rehabilitation provider according to the "Guidelines on the referral of visually impaired persons to low-vision services" [39]. According to these evidence-based guidelines, persons with a visual acuity $<0.3$ and/or visual field $<30$ degrees in the better eye, and persons with a visual acuity $<0.5$ who experience problems in daily life should be referred to a low-vision rehabilitation center. From this sample, 264 persons were eligible for this study and 173 persons consented to participate (response 66\%). A flow diagram and detailed information about the inclusion procedure are published elsewhere [12]. Non-response analysis showed that study participants (mean age 72.3 [SD 9.7]) were younger than non-respondents (mean age 78.5 [SD 9.7]; $t=-4.98$, 
$P<0.001)$. No difference was found with respect to gender.

\section{Design}

Data for this cross-sectional study were collected by means of telephone interviews performed by experienced interviewers. Participants gave informed consent before the interview. The study complied with the Code of Ethics of the Declaration of Helsinki and was reviewed by the Medical Ethics Review Committee of the University Medical Center Groningen.

Measures

\section{Participation}

In line with the ICF, we defined participation as "involvement in life situations" [15]. The ICF lists nine chapters that cover the full range of "Activities and Participation" and gives several options for differentiating "Participation" from "Activities". We applied one option, which is in line with Post et al. [40], by identifying four chapters that represent participation: (1) domestic life; (2) interpersonal interactions and relationships; (3) major life areas; and (4) community, social, and civic life. To measure participation, we linked items from available population surveys [41-43] to each of the four ICF chapters and included them in the interview schedule. We performed seven pilot interviews which resulted in minor revisions of the interview schedule.

Participation in domestic life included light household activities, heavy household activities, assisting others, and shopping. Performance of these activities was assessed as a dichotomous variable (yes/no) which was summed to obtain a domestic life participation score (range 0-4).

Interpersonal interactions and relationships were operationalized as socializing, defined as meeting relatives, friends, or neighbors in person (including contact by telephone or e-mail). Persons who socialized once a week or more were classified as frequently socializing (yes/no). The three scores were summed to obtain a participation score for interpersonal interactions and relationships (range 0-3).

Participation in major life areas included participation in voluntary work, defined as doing unpaid work in organized associations and was assessed as a dichotomous variable (yes/no). Since the majority of the study population was retired, we did not assess paid work.

The community, social, and civic life domain included involvement in clubs or associations (yes/no); hobby activities (yes if $\geq 1 \times /$ week); sports activities (yes/no); going to recreational places, cultural places, and public places (yes if $\geq 1 \times /$ month, respectively); going on holidays (yes if $\geq 1 \times /$ year); and involvement in religious activities (yes if $\geq 1 \times /$ month). The scores for these eight items were summed to obtain a participation score for the community, social, and civic life domain (range 0-8).

Personal values regarding participation were operationalized as the importance of a particular domain, as perceived by the individual, and was assessed with the importance subscale of the participation assessment with recombined tools-satisfaction (PART-S) [44]. Participants rated each domain as being of low, medium, or high importance (score 1-3). The "housekeeping and other activities to keep your home in good order" item was used as an indicator of the importance of participation in domestic life. The mean of the two items "relationships with family and relatives" and "relationships with friends and acquaintances" was used as an indicator of the importance of interpersonal interactions and relationships. The "unpaid work" item covered the importance of participation in major life areas. The mean of the items "participation in religious services", "activities in other organizations", and "recreation and leisure, whether at home or elsewhere" was used as an indicator of the importance of participation in community, social, and civic life.

\section{Sociodemographic characteristics}

Age, gender, educational level (based on the International Standard Classification of Education [ISCED] [45]), and income were used as sociodemographic characteristics.

\section{Physical health status}

Self-perceived vision was measured by the single-item "general vision" subscale of the visual functioning questionnaire (VFQ-25) [46], which was transformed into a score ranging from 0 to $100(M=40.1$ [SD 18.8]). Degree of visual impairment, defined as visual acuity in the better eye, was collected from the medical files available at the low-vision rehabilitation centers of Royal Dutch Visio. Visual acuity values were transformed to $\log$ MAR values ( $-\log$ visual acuity). Duration of visual impairment was computed by subtracting the self-reported age of onset of vision loss from a participant's age.

Fatigue was assessed with the four-item "general fatigue" subscale of the multidimensional fatigue inventory (MFI) [47]. Scale scores ranged from 4 to $20(M=11.3$ [SD 4.9]; $\alpha=0.82$ ). Perceived physical fitness was assessed with a ten-item subscale of the Groningen fitness test for the elderly (GFE) [48], which is a comparative fitness rating using peers as a frame of reference. Scale scores ranged from 10 to $50 \quad(M=27.9$ [SD 7.4]; $\alpha=0.87)$. Comorbidity was assessed using an open-ended question that asked participants to list all their chronic conditions (median $=1$; range $0-5$ ). 


\section{Social status}

Partner status was defined as having a partner, irrespective of cohabitation, or being single. Social network was assessed by four questions addressing the number of individuals within the personal network of children, relatives, friends, and neighbors. The sum score reflects the total network size $(M=20.5$ [SD 13.4]). The Social Support List (subscale negative interactions [49]) assessed negative social support with seven items on a 1-4 Likert scale. Scale scores ranged from 7 to $28(M=9.3$ [SD 2.5]; $\alpha=0.71)$

\section{Psychological status}

Mental health was assessed with the five-item subscale of the RAND-36 [50, 51] including items on depression and nervousness. Raw scale scores were converted to a 0-100 scale $(M=69.9$ [SD 18.8]; $\alpha=0.79)$. Helplessness was assessed with the six-item subscale of the illness cognition questionnaire (ICQ) [52]. Scale scores ranged from 6 to 24 $(M=13.6$ [SD 4.8]; $\alpha=0.84)$. The self-management ability scale (SMAS-30; version 1, 2004) [53] was used to measure two self-management abilities, e.g., self-efficacy and taking initiatives. Scale scores for these two five-item subscales ranged from 5 to 30 (self-efficacy $M=20.6$ [SD 3.9] $\alpha=0.74$; taking initiatives $M=18.7$ [SD 4.3] $\alpha=0.68$ ).

\section{Statistical analysis}

Non-response analysis was performed using the Student's $t$ test and Chi-square test. Missing values were imputed according to the instructions of the questionnaires. If no instructions were available, missing values were replaced with the average score of the completed items in the scale, provided that at least $50 \%$ of the items were completed.

Multivariate hierarchical regression analyses (balanced design) were performed to examine the association between the outcome measures (i.e., participation in domestic life, interpersonal interactions and relationships, and community, social, and civic life) and the potential explanatory factors (i.e., sociodemographic, physical health, social and psychological factors, and personal values). Variables that were univariately associated with a specific participation domain $(P<0.05)$ were entered into the model. The entry of the variables was as follows: block 1) sociodemographic factors; block 2) physical health status; block 3) social status; block 4) psychological status; and block 5) personal values. The results were checked for multicollinearity and were below the critical multicollinearity values (correlation coefficient $<0.80$ [54] and variance inflation factor $<10$ [55]). Logistic regression analysis was performed for the binary outcome measure of participation in major life areas. The entry of the variables was the same as in the multivariate hierarchical regression analyses. All analyses were performed using the statistical package for the social sciences (SPSS, Inc, Chicago, IL, USA), version 16.0.

\section{Results}

Descriptive characteristics of the 173 study participants are shown in Table 1.

Domestic life

Participation domain scores in domestic life ranged from 0 to 4 ( $M=2.6$ [SD 1.1]). Four percent of the study group did not participate in any of the four domestic life activities, whereas $23 \%$ participated in all activities. Univariate analyses showed that age, fatigue, perceived physical fitness, partner status, mental health, helplessness, self-efficacy, and taking initiatives were statistically significantly associated with participation in domestic life (Table 2). The other explanatory variables, including vision-related characteristics, were not associated with domestic life (range Beta: $0.01-0.10 ; P \geq 0.19$; data not shown). Multivariate hierarchical regression analysis (Table 2) showed that in the final model, Model 4, 28.3\% of the total variance in participation in domestic life could be explained. Younger age, favorable perceived physical fitness, and less helplessness were associated with more participation in domestic life.

Interpersonal interactions and relationships

Fifty percent of the study group had the maximum score on participation in interpersonal interactions and relationship ( $M=2.3$ [SD 0.8]; range: 0-3). Univariate analyses with participation in interpersonal interactions and relationships as dependent variable (Table 3) showed statistically significant associations for fatigue, perceived physical fitness, social network size, self-efficacy, taking initiatives, and perceived importance. No significant associations were found for the other explanatory variables (range Beta: $0.01-0.15 ; P \geq 0.06$; data not shown). The results of the multivariate regression analysis (Table 3 ) indicated that variables representing physical health status and psychological status were not statistically significantly related to participation in interpersonal interactions and relationships; only perceived importance was a significant determinant (Model 4; explained variance 14.5\%). A higher perceived importance of relationships with family and friends was associated with a higher frequency of interactions in this domain. 
Table 1 Sociodemographic and vision-related characteristics, and comorbidity of the study participants $(n=173)$

$S D$ Standard deviation, $V F Q$

Visual Functioning

Questionnaire, VODS Visus

Oculi Dextri Sinistri

${ }^{a}$ Percentages are based on totals for each category, and may not total 100 because of rounding

b e.g., diabetic retinopathy

c e.g., retinitis pigmentosa

d number of chronic conditions other than the eye-disease

\begin{tabular}{|c|c|}
\hline Characteristic & Value $-n(\%)^{\mathrm{a}}$ \\
\hline \multicolumn{2}{|l|}{ Age, years } \\
\hline $55-74$ & $103(60)$ \\
\hline$\geq 75$ & $70(40)$ \\
\hline Mean $\pm \mathrm{SD}$ & $72.3 \pm 9.7$ \\
\hline Range & $55-93$ \\
\hline Gender, female & $100(58)$ \\
\hline Partner status, partner & $83(52)$ \\
\hline \multicolumn{2}{|l|}{ Educational level } \\
\hline (Pre)primary & $25(16)$ \\
\hline Lower secondary & $47(30)$ \\
\hline Upper secondary & $53(34)$ \\
\hline Tertiary & $33(21)$ \\
\hline \multicolumn{2}{|l|}{ Income } \\
\hline$<€ 1,500$ a month & $58(45)$ \\
\hline$€ 1,500-€ 2,999$ a month & $57(45)$ \\
\hline$\geq € 3,000$ a month & $13(10)$ \\
\hline \multicolumn{2}{|l|}{ VFQ-25 } \\
\hline Poor, very poor, or completely blind & $118(71)$ \\
\hline Fair, good, or excellent & $48(29)$ \\
\hline Mean \pm SD & $40.1 \pm 18.8$ \\
\hline \multicolumn{2}{|l|}{ Binocular visual acuity (VODS) } \\
\hline Median & 0.25 \\
\hline Mean \pm SD & $0.75 \log \mathrm{MAR} \pm 0.65 \log \mathrm{MAR}$ \\
\hline \multicolumn{2}{|l|}{ Duration of vision loss, years } \\
\hline Median & 7 \\
\hline \multicolumn{2}{|l|}{ Primary cause of visual impairment } \\
\hline Age-related maculopathy & $81(49)$ \\
\hline Vascular disorders ${ }^{\mathrm{b}}$ & $12(7)$ \\
\hline Optic nerve disorders & $10(6)$ \\
\hline Congenital and hereditary disorders ${ }^{c}$ & $7(4)$ \\
\hline Corneal disorders & $5(3)$ \\
\hline Glaucoma & $4(2)$ \\
\hline Cataract & $4(2)$ \\
\hline Other primary causes & $12(7)$ \\
\hline Combination of causes & $22(13)$ \\
\hline Cause unknown & $10(6)$ \\
\hline \multicolumn{2}{|l|}{ Comorbidity $^{\mathrm{d}}$} \\
\hline None & $74(45)$ \\
\hline 1 & $56(34)$ \\
\hline$\geq 2$ & $35(21)$ \\
\hline
\end{tabular}

\section{Major life areas}

Twenty-seven percent of the study participants were involved in major life areas. The results of the univariate logistic regression analyses with voluntary work as the dependent variable (Table 4) showed an association for age, fatigue, partner status, social network size, mental health, helplessness, taking initiatives, and perceived importance. The other explanatory variables were not significantly associated with voluntary work (range OR: 0.54-1.15; $P \geq 0.08$; data not shown). Multivariate logistic regression analysis showed that in the final model, perceived importance was a significant determinant of participation in major life areas, in addition to social network size. 
Table 2 Univariate and multivariate regression analyses of participation in domestic life on sociodemographic characteristics, physical health status, social status, psychological status, and personal values

\begin{tabular}{|c|c|c|c|c|c|}
\hline & $\begin{array}{l}\text { Univariate } \\
\text { Beta }\end{array}$ & $\begin{array}{l}\text { Model } 1 \\
\text { Beta }\end{array}$ & $\begin{array}{l}\text { Model } 2 \\
\text { Beta }\end{array}$ & $\begin{array}{l}\text { Model } 3 \\
\text { Beta }\end{array}$ & $\begin{array}{l}\text { Model } 4 \\
\text { Beta }\end{array}$ \\
\hline \multicolumn{6}{|c|}{ Sociodemographic characteristics $(8.8 \%)^{\mathrm{a}}$} \\
\hline Age & $-0.30 * * *$ & $-0.30 * * *$ & $-0.33 * * *$ & $-0.31 * * *$ & $-0.22 * *$ \\
\hline \multicolumn{6}{|l|}{ Physical health status $(11.3 \%)^{\mathrm{a}}$} \\
\hline Fatigue & $-0.32 * * *$ & & -0.11 & -0.11 & -0.10 \\
\hline Perceived physical fitness & $0.32 * * *$ & & $0.29 * *$ & $0.29 * *$ & $0.19 *$ \\
\hline \multicolumn{6}{|l|}{ Social status $(2.5 \%)^{\mathrm{a}}$} \\
\hline Partner status (partner) & $0.16^{*}$ & & & 0.08 & 0.07 \\
\hline \multicolumn{6}{|l|}{ Psychological status $(20.6 \%)^{\mathrm{a}}$} \\
\hline Mental health & $0.22 * *$ & & & & -0.07 \\
\hline Helplessness & $-0.35^{* * *}$ & & & & $-0.19 *$ \\
\hline Self-efficacy & $0.36 * * *$ & & & & 0.07 \\
\hline Taking initiatives & $0.37 * * *$ & & & & 0.13 \\
\hline \multicolumn{6}{|l|}{ Personal values $(0.0 \%)^{\mathrm{a}}$} \\
\hline$R^{2}$-change $(\%)$ & & 8.8 & 12.8 & 0.5 & 6.2 \\
\hline Total $R^{2}(\%)$ & & 8.8 & 21.6 & 22.1 & 28.3 \\
\hline $\mathrm{F}$ & & $14.7 * * *$ & $13.8 * * *$ & $10.6 * * *$ & $7.2 * * *$ \\
\hline$n$ & & 154 & 154 & 154 & 154 \\
\hline
\end{tabular}

Beta standardized regression coefficient

${ }^{a}$ Explained variance of the separate block

$* P<0.05 ; * * P<0.01 ; * * * P<0.001$

Table 3 Univariate and multivariate regression analyses of participation in interpersonal interactions and relationships on sociodemographic characteristics, physical health status, social status, psychological status, and personal values

\begin{tabular}{|c|c|c|c|c|c|}
\hline & $\begin{array}{l}\text { Univariate } \\
\text { Beta }\end{array}$ & $\begin{array}{l}\text { Model } 1 \\
\text { Beta }\end{array}$ & $\begin{array}{l}\text { Model } 2 \\
\text { Beta }\end{array}$ & $\begin{array}{l}\text { Model } 3 \\
\text { Beta }\end{array}$ & $\begin{array}{l}\text { Model } 4 \\
\text { Beta }\end{array}$ \\
\hline \multicolumn{6}{|c|}{ Sociodemographic characteristics $(0.0 \%)^{\mathrm{a}}$} \\
\hline \multicolumn{6}{|l|}{ Physical health status $(2.6 \%)^{\mathrm{a}}$} \\
\hline Fatigue & $-0.17 *$ & -0.10 & -0.09 & -0.08 & -0.08 \\
\hline Perceived physical fitness & $0.18 *$ & 0.08 & 0.06 & 0.03 & 0.06 \\
\hline \multicolumn{6}{|l|}{ Social status $(6.8 \%)^{\mathrm{a}}$} \\
\hline Social network size & $0.26 * *$ & & $0.25 * *$ & $0.21 *$ & 0.14 \\
\hline \multicolumn{6}{|l|}{ Psychological status $(4.7 \%)^{\mathrm{a}}$} \\
\hline Self-efficacy & $0.23 * *$ & & & 0.09 & 0.05 \\
\hline Taking initiatives & $0.22 * *$ & & & 0.01 & 0.00 \\
\hline \multicolumn{6}{|l|}{ Personal values $(9.8 \%)^{\mathrm{a}}$} \\
\hline Perceived importance & $0.26 * * *$ & & & & $0.25 * *$ \\
\hline$R^{2}$-change $(\%)$ & & 2.6 & 5.9 & 0.6 & 5.4 \\
\hline Total $R^{2}(\%)$ & & 2.6 & 8.5 & 9.1 & 14.5 \\
\hline $\mathrm{F}$ & & 1.9 & $4.4 * *$ & $2.8^{*}$ & $4.0 * *$ \\
\hline$n$ & & 148 & 148 & 148 & 148 \\
\hline
\end{tabular}

Beta standardized regression coefficient

a Explained variance of the separate block

* $P<0.05$; ** $P<0.01$ 
Community, social, and civic life

Participation scores on the community, social, and civic life domain ranged from 0 to $7(M=3.0$ [SD 1.6]). The results of the univariate regression analyses (Table 5) showed that age, income, fatigue, perceived physical fitness, partner status, social network size, helplessness, selfefficacy, taking initiatives, and perceived importance were statistically significantly associated with participation in this domain. No significant associations were found for the other explanatory variables (range Beta: 0.02-0.15; $P \geq 0.06$; data not shown). The results of the multivariate regression analysis showed that only perceived importance was associated with more participation in this domain (Model 5; explained variance 28.2\%).

\section{Discussion}

The purpose of this study was to assess the determinants of self-reported performance of participation in domestic life, interpersonal interactions and relationships, major life areas, and community, social and civic life among visually impaired older adults. These determinants were investigated according to the biopsychosocial model.
With respect to vision-related variables, we found that the severity, duration, and primary cause of VI had no effect on participation. This is in accordance with the study of Desrosiers et al. [37] who found that visual acuity was not associated with participation. Other measures of visual functioning (e.g., visual field, contrast sensitivity, acuteness of the onset of vision loss) may have had an impact on participation. However, these measures were not included in our study, because of the unavailability of these data for all study participants. It is beyond question that visually impaired older adults do perceive restrictions in participation [4, 11, 12]. Our results indicate that, although a visual impairment leads to participation restrictions, the severity of the impairment in itself has no impact on participation of visually impaired older adults.

The finding that perceived physical fitness is a determinant of participation in domestic life is not surprising, given that doing household tasks requires exertion of the physiological system (muscle mass and strength, flexibility, balance and coordination, and cardiovascular function). The association between physical fitness and participation was also found in the study of Anaby et al. [31] among older adults in general, which showed that balance and mobility affected participation in daily activities and social roles. Lamoureux et al. [11] found that physical

Table 4 Univariate and multivariate logistic regression analyses of participation in major life areas on sociodemographic characteristics, physical health status, social status, psychological status, and personal values

\begin{tabular}{|c|c|c|c|c|c|c|}
\hline & $\begin{array}{l}\text { Univariate } \\
\text { OR }(95 \% \mathrm{CI})\end{array}$ & $\begin{array}{l}\text { Model } 1 \\
\text { OR }(95 \% \mathrm{CI})\end{array}$ & $\begin{array}{l}\text { Model } 2 \\
\text { OR }(95 \% \text { CI })\end{array}$ & $\begin{array}{l}\text { Model } 3 \\
\text { OR }(95 \% \text { CI })\end{array}$ & $\begin{array}{l}\text { Model } 4 \\
\text { OR }(95 \% \mathrm{CI})\end{array}$ & $\begin{array}{l}\text { Model } 5 \\
\text { OR }(95 \% \text { CI })\end{array}$ \\
\hline \multicolumn{7}{|c|}{ Sociodemographic variables } \\
\hline Age & $0.96(0.92-0.99)^{*}$ & $0.97(0.93-1.00)$ & $0.97(0.93-1.01)$ & $0.98(0.94-1.02)$ & $0.99(0.94-1.03)$ & $0.99(0.94-1.04)$ \\
\hline \multicolumn{7}{|c|}{ Physical health status } \\
\hline Fatigue & $0.91(0.84-0.97)^{* *}$ & & $0.92(0.85-0.99)^{*}$ & $0.92(0.85-1.00)^{*}$ & $0.94(0.85-1.03)$ & $0.92(0.83-1.02)$ \\
\hline \multicolumn{7}{|l|}{ Social status } \\
\hline $\begin{array}{l}\text { Partner status } \\
\text { (partner) }\end{array}$ & $2.08(1.02-4.24)^{*}$ & & & $1.52(0.68-3.43)$ & $1.63(0.71-3.74)$ & $1.64(0.63-4.24)$ \\
\hline $\begin{array}{l}\text { Social } \\
\text { network size }\end{array}$ & $1.03(1.00-1.05)^{*}$ & & & $1.03(1.00-1.06)$ & $1.02(0.99-1.05)$ & $1.04(1.00-1.07)^{*}$ \\
\hline \multicolumn{7}{|c|}{ Psychological status } \\
\hline Mental health & $1.02(1.00-1.04) *$ & & & & $1.00(0.97-1.02)$ & $1.01(0.98-1.04)$ \\
\hline Helplessness & $0.90(0.83-0.97)^{* *}$ & & & & $0.92(0.84-1.01)$ & $0.96(0.87-1.07)$ \\
\hline $\begin{array}{l}\text { Taking } \\
\text { initiatives }\end{array}$ & $1.10(1.01-1.20)^{*}$ & & & & $1.02(0.92-1.13)$ & $0.95(0.83-1.07)$ \\
\hline \multicolumn{7}{|l|}{ Personal values } \\
\hline $\begin{array}{l}\text { Perceived } \\
\text { importance }\end{array}$ & $3.35(2.15-5.22) * * *$ & & & & & $3.78(2.19-6.50) * *$ \\
\hline 2 log likelihood & & 180.5 & 175.6 & 169.6 & 139.5 & 137.9 \\
\hline$N$ & & 151 & 151 & 151 & 151 & 151 \\
\hline
\end{tabular}

CI 95\% confidence interval, $O R$ odds ratio

$* P<0.05$; ** $P<0.001$ 
Table 5 Univariate and multivariate regression analyses of participation in community, social, and civic life on sociodemographic characteristics, physical health status, social status, psychological status, and personal values

\begin{tabular}{|c|c|c|c|c|c|c|}
\hline & $\begin{array}{l}\text { Univariate } \\
\text { Beta }\end{array}$ & $\begin{array}{l}\text { Model } 1 \\
\text { Beta }\end{array}$ & $\begin{array}{l}\text { Model } 2 \\
\text { Beta }\end{array}$ & $\begin{array}{l}\text { Model } 3 \\
\text { Beta }\end{array}$ & $\begin{array}{l}\text { Model } 4 \\
\text { Beta }\end{array}$ & $\begin{array}{l}\text { Model } 5 \\
\text { Beta }\end{array}$ \\
\hline \multicolumn{7}{|c|}{ Sociodemographic variables $(7.9 \%)^{\mathrm{a}}$} \\
\hline Age & $-0.15^{*}$ & -0.13 & -0.15 & -0.09 & -0.04 & -0.07 \\
\hline Income & $0.26 * *$ & $0.24 * *$ & $0.22 *$ & 0.11 & 0.10 & 0.10 \\
\hline \multicolumn{7}{|l|}{ Physical health status $(8.8 \%)^{\mathrm{a}}$} \\
\hline Fatigue & $-0.22 * *$ & & -0.15 & -0.12 & -0.09 & -0.07 \\
\hline Perceived physical fitness & $0.23 * *$ & & 0.18 & $0.21 *$ & 0.15 & 0.20 \\
\hline \multicolumn{7}{|l|}{ Social status $(9.2 \%)^{\mathrm{a}}$} \\
\hline Partner status (partner) & $0.22 * *$ & & & 0.20 & $0.22 *$ & 0.19 \\
\hline Social network size & $0.22 * *$ & & & 0.06 & 0.02 & -0.00 \\
\hline \multicolumn{7}{|l|}{ Psychological status $(11.9 \%)^{\mathrm{a}}$} \\
\hline Helplessness & $-0.30 * * *$ & & & & -0.17 & -0.12 \\
\hline Self-efficacy & $0.32 * * *$ & & & & 0.06 & 0.04 \\
\hline Taking initiatives & $0.29 * * *$ & & & & 0.02 & 0.05 \\
\hline \multicolumn{7}{|l|}{ Personal values $(8.2 \%)^{\mathrm{a}}$} \\
\hline Perceived importance & $0.32 * * *$ & & & & & $0.24 * *$ \\
\hline$R^{2}$-change $(\%)$ & & 7.9 & 8.2 & 3.4 & 3.4 & 5.3 \\
\hline Total $R^{2}(\%)$ & & 7.9 & 16.1 & 19.5 & 22.9 & 28.2 \\
\hline$F$ & & $5.0 * *$ & $5.5 * * *$ & $4.6^{* * * *}$ & $3.6^{* *}$ & $4.3^{* * *}$ \\
\hline$N$ & & 120 & 120 & 120 & 120 & 120 \\
\hline
\end{tabular}

Beta standardized regression coefficient

${ }^{\text {a }}$ Explained variance of the separate block

* $P<0.05$; ** $P<0.01$; *** $P<0.001$

functioning was one of the main predictors of participation restrictions among people with impaired vision. Our finding indicates that physical fitness may be an important prerequisite for participation. This knowledge can be used for the development of rehabilitative interventions.

With respect to the social status variables, only social network size was associated with participation in major life areas (i.e., voluntary work). To our knowledge, this relationship has not been studied before. Unexpectedly, social support appeared not to be related to participation. This is in contrast with the positive effect of support of family and friends on participation, as found in older adults in general [32]. We used negative interactions as an indicator of social support instead of positive aspects, such as stimulation or encouragement, which may explain the difference in findings regarding social support. Our choice to use negative social interactions as an indicator of social support was based on previous research in visually impaired older adults [56]. The low prevalence of negative social interactions in our study population, however, may also explain the lack of association between social support and participation.

The psychological status variables (i.e., mental health, helplessness, self-efficacy, and taking initiatives) contributed to the explained variance of participation across the domains. However, a significant association was only found for the domestic life domain; a higher level of helplessness was associated with decreased participation in domestic life. Helplessness refers to an attributional style, explaining negative events and their consequences as uncontrollable, unpredictable, and unchangeable [52]. Negative outcome expectancies and negative attributions with regard to vision loss may lead to avoidance behavior. To our knowledge, only Lindo and Nordholm [57] assessed the relationship between helplessness and participation. In a sample of visually impaired adults of working age, they found that helplessness was associated with perceived difficulties in cleaning the home, shopping, leisure activities, and socializing. Despite the modest associations we found in the multivariate models, it seems important to assess psychological functioning in relation to participation [37].

Perceived importance of participation appeared to be a major determinant in three out of the four participation domains (i.e., interpersonal interactions and relationships, major life areas, and community, social and civic life). Importance refers to the value that an individual attaches to a specific domain and may influence the motivation and 
choice to engage in a specific domain of participation. In the domestic life domain, however, we found no association for perceived importance. This may be explained by the fact that household activities and shopping are necessities of daily life, irrespective of how one values these activities.

One of the limitations of the present study is the crosssectional design which limits the inferences of causality. The inclusion of study participants from a low-vision rehabilitation center may imply the selection of relatively motivated visually impaired older adults. Furthermore, the self-report data derived through telephone interviews may imply social desirability bias. With respect to the outcome measure of the study, there is no consensus yet on how participation should be measured [58]. At the time of data collection, we concluded, based on a review of Perenboom and Chorus [59] and on our own literature review, that there was no participation questionnaire available that suited the aim of our study, namely to measure selfreported performance of participation. Therefore, we assessed participation by means of items extracted from available population surveys [41-43], and computed participation domain scores by a summation of the frequency of activities. The actual scores, however, are less than the theoretical maximum because of the limits to a person's time, resources and energy [60]. We followed one of the options given by the ICF for differentiating "Participation" from "Activities", and identified four chapters that represent participation. Whether the "Domestic life" chapter is a domain of participation, or whether it is merely connected to activities, is debatable. Whiteneck and Dijkers [61] recently stated that this chapter is the most difficult to allocate to activity versus participation, and concluded that domestic life focused mainly on individual activities. If so, this may be another explanation that perceived importance was not related to participation in domestic life activities.

Despite the comprehensive biopsychosocial model, the variance in participation could only partially be explained (range 14.5-28.3\%). The low explained variance of participation in interpersonal interactions and relationships may be caused by the positively skewed distribution and consequently small variance of this outcome measure. Another reason may be that participation has multiple determinants which makes it difficult to explain participation more accurately [62]. Factors that were not included in our study may have been a barrier for participation of our study participants, such as the availability of (public) transport and accessibility of (public) buildings.

To our knowledge, this is the first study that applied a biopsychosocial model in order to investigate determinants of self-reported performance of participation in visually impaired older adults. Knowledge of the factors that influence participation is relevant, since participation contributes to quality of life and well-being [18-20]. The results of the present study may guide the development of future low-vision rehabilitation interventions. The relevance of personal values attached to participation in specific domains underlines the need to assess these values before starting rehabilitation in order to facilitate individual goal-setting. Furthermore, interventions should have a multidisciplinary approach, including physical, psychological and social work intervention techniques. Group rehabilitation, instead of an individual approach, is advised because it facilitates sharing experiences and coping strategies between the visually impaired, and may extend the social network. Future studies are needed to study the effectiveness of multidisciplinary group rehabilitation interventions on participation in society.

Acknowledgments The study was supported by a grant (number: 94304003) from the Netherlands Organisation for Health Research and Development (ZonMw), research program "InSight", appointed by the Ministry of Health (VWS) and the Netherlands Organisation for Scientific Research (NWO). The authors would like to thank Royal Dutch Visio for their cooperation in the study. In addition, we are grateful to those people who participated in the study.

Conflict of interest The authors declare that they have no conflict of interest.

Open Access This article is distributed under the terms of the Creative Commons Attribution Noncommercial License which permits any noncommercial use, distribution, and reproduction in any medium, provided the original author(s) and source are credited.

\section{References}

1. Limburg, H. (2007). Epidemiology of visual impairment in The Netherlands and a demographic exploration. Health Information Services. http://www.zonmw.nl/fileadmin/cm/langdurende_zorg/ InZicht/InZicht_project_94306001_versie_21.pdf. Accessed 5 June 2009.

2. Horowitz, A. (2004). The prevalence and consequences of vision impairment in later life. Topics in Geriatric Rehabilitation, 20(5), $185-195$.

3. Heyl, V., \& Wahl, H. W. (2001). Psychosocial adaptation to agerelated vision loss: A six-year perspective. Journal of Visual Impairment and Blindness, 95(12), 739-748.

4. Lamoureux, E. L., Hassell, J. B., \& Keeffe, J. E. (2004). The impact of diabetic retinopathy on participation in daily living. Archives of Ophthalmology, 122(1), 84-88.

5. West, S. K., Rubin, G. S., Broman, A. T., Munoz, B., BandeenRoche, K., \& Turano, K. (2002). How does visual impairment affect performance on tasks of everyday life? The SEE project. Archives of Ophthalmology, 120(6), 774-780.

6. Crews, J. E., \& Campbell, V. A. (2001). Health conditions, activity limitations, and participation restrictions among older people with visual impairments. Journal of Visual Impairment and Blindness, 95(8), 453-467.

7. Crews, J. E., \& Campbell, V. A. (2004). Vision impairment and hearing loss among community-dwelling older Americans: 
Implications for health and functioning. American Journal of Public Health, 94(5), 823-829.

8. Knudtson, M. D., Klein, B. E., Klein, R., Cruickshanks, K. J., \& Lee, K. E. (2005). Age-related eye disease, quality of life, and functional activity. Archives of Ophthalmology, 123(6), 807-814.

9. Hassell, J. B., Lamoureux, E. L., \& Keeffe, J. E. (2006). Impact of age related macular degeneration on quality of life. British Journal of Ophthalmology, 90(5), 593-596.

10. Rubin, G. S., Bandeen-Roche, K., Huang, G. H., Munoz, B., Schein, O. D., Fried, L. P., et al. (2001). The association of multiple visual impairments with self-reported visual disability: SEE project. Investigative Ophthalmology and Visual Science, 42(1), 64-72.

11. Lamoureux, E. L., Hassell, J. B., \& Keeffe, J. E. (2004). The determinants of participation in activities of daily living in people with impaired vision. American Journal of Ophthalmology, 137(2), 265-270.

12. Alma, M. A., Van der Mei, S. F., Melis-Dankers, B. J., Van Tilburg, T. G., Groothoff, J. W., \& Suurmeijer, T. P. (2011). Participation of the elderly after vision loss. Disability and Rehabilitation, 33(1), 63-72.

13. Rovner, B. W., \& Casten, R. J. (2002). Activity loss and depression in age-related macular degeneration. American Journal of Geriatric Psychiatry, 10(3), 305-310.

14. West, S. K., Munoz, B., Rubin, G. S., Schein, O. D., BandeenRoche, K., Zeger, S., et al. (1997). Function and visual impairment in a population-based study of older adults. The SEE project. Salisbury eye evaluation. Investigative Ophthalmology and Visual Science, 38(1), 72-82.

15. World Health Organization. (2001). ICF: International classification of functioning, disability and health. Geneva: World Health Organization.

16. Whiteneck, G. (2005). Conceptual models of disability: Past, present \& future. In M. J. Field, A. M. Jette, \& L. Martin (Eds.), Workshop on disability in America (pp. 50-60). Washington, DC: National Academics Press.

17. WHOQOL. (1995). The World Health Organization quality of life assessment (WHOQOL): Position paper from the World Health Organization. Social Science and Medicine, 41(10), 1403-1409.

18. Levasseur, M., Desrosiers, J., \& Noreau, L. (2004). Is social participation associated with quality of life of older adults with physical disabilities? Disability and Rehabilitation, 26(20), $1206-1213$.

19. Levasseur, M., Desrosiers, J., \& St-Cyr Tribble, D. (2008). Do quality of life, participation and environment of older adults differ according to level of activity? Health and Quality of Life Outcomes, 6, 30.

20. Bowling, A., Gabriel, Z., Dykes, J., Dowding, L. M., Evans, O., Fleissig, A., et al. (2003). Let's ask them: A national survey of definitions of quality of life and its enhancement among people aged 65 and over. International Journal of Aging and Human Development, 56(4), 269-306.

21. Hammel, J., Magasi, S., Heinemann, A., Whiteneck, G., Bogner, J., \& Rodriguez, E. (2008). What does participation mean? An insider perspective from people with disabilities. Disability and Rehabilitation, 30(19), 1445-1460.

22. Glei, D. A., Landau, D. A., Goldman, N., Chuang, Y. L., Rodriguez, G., \& Weinstein, M. (2005). Participating in social activities helps preserve cognitive function: An analysis of a longitudinal, population-based study of the elderly. International Journal of Epidemiology, 34(4), 864-871.

23. Avlund, K., Lund, R., Holstein, B. E., \& Due, P. (2004). Social relations as determinant of onset of disability in aging. Archives of Gerontology and Geriatrics, 38(1), 85-99.
24. Stuck, A. E., Walthert, J. M., Nikolaus, T., Bula, C. J., Hohmann, C., \& Beck, J. C. (1999). Risk factors for functional status decline in community-living elderly people: A systematic literature review. Social Science and Medicine, 48(4), 445-469.

25. Wilkie, R., Peat, G., Thomas, E., \& Croft, P. (2006). The prevalence of person-perceived participation restriction in community-dwelling older adults. Quality of Life Research, 15(9), 1471-1479.

26. Bukov, A., Maas, I., \& Lampert, T. (2002). Social participation in very old age: Cross-sectional and longitudinal findings from BASE. Berlin Aging Study. Journals of Gerontology. Series B, Psychological Sciences and Social Sciences, 57(6), 510-517.

27. Agahi, N., \& Parker, M. (2005). Are today's older people more active than their predecessors? Participation in leisure-time activities in Sweden in 1992 and 2002. Ageing and Society, 25(6), 925-941.

28. Hyland, M. E., Sodergren, S. C., \& Singh, S. J. (1999). Variety of activity: Relationship with health status, demographic variables and global quality of life. Psychology, Health and Medicine, 4(3), 241-254.

29. Broese van Groenou, M. (2006). Social participation of the 55-64 year olds: Is the new generation more socially active than its predecessor? Tijdschrift voor Gerontologie en Geriatrie, 37(6), 218-225.

30. Wilkie, R., Peat, G., Thomas, E., \& Croft, P. (2007). Factors associated with participation restriction in community-dwelling adults aged 50 years and over. Quality of Life Research, 16(7), $1147-1156$.

31. Anaby, D., Miller, W. C., Eng, J. J., Jarus, T., \& Noreau, L. (2009). Can personal and environmental factors explain participation of older adults? Disability and Rehabilitation, 31(15), $1275-1282$.

32. Vik, K., Lilja, M., \& Nygard, L. (2007). The influence of the environment on participation subsequent to rehabilitation as experienced by elderly people in Norway. Scandinavian Journal of Occupational Therapy, 14(2), 86-95.

33. Cardol, M., De Jong, B. A., Van den Bos, G. A., Beelem, A., De Groot, I. J., \& De Haan, R. J. (2002). Beyond disability: Perceived participation in people with a chronic disabling condition. Clinical Rehabilitation, 16(1), 27-35.

34. Bent, N., Jones, A., Molloy, I., Chamberlain, M. A., \& Tennant, A. (2001). Factors determining participation in young adults with a physical disability: A pilot study. Clinical Rehabilitation, 15(5), $552-561$.

35. Dumont, C., Gervais, M., Fougeyrollas, P., \& Betrand, R. (2004). Toward an explanatory model of social participation for adults with traumatic brain injury. Journal of Head Trauma Rehabilitation, 19(6), 431-444.

36. Fishbein, M. (1967). Readings in attitude theory and measurement. New York: John Wiley.

37. Desrosiers, J., Wanet-Defalque, M. C., Temisjian, K., Gresset, J., Dubois, M. F., Renaud, J., et al. (2009). Participation in daily activities and social roles of older adults with visual impairment. Disability and Rehabilitation, 31(15), 1227-1234.

38. Noe, G., Ferraro, J., Lamoureux, E., Rait, J., \& Keeffe, J. E. (2003). Associations between glaucomatous visual field loss and participation in activities of daily living. Clinical and Experimental Ophthalmology, 31(6), 482-486.

39. De Boer, M. R., Langelaan, M., Jansonius, N. M., \& Van Rens, G. H. (2005). Evidence-based guidelines on the referral of visually impaired persons to low vision services. European Journal of Ophthalmology, 15(3), 400-406.

40. Post, M. W., De Witte, L. P., Reichrath, E., Verdonschot, M. M., Wijlhuizen, G. J., \& Perenboom, R. J. (2008). Development and validation of IMPACT-S, an ICF-based questionnaire to measure 
activities and participation. Journal of Rehabilitation Medicine, 40(8), 620-627.

41. Social and Cultural Planning Office of the Netherlands. (2004). Amenities and services utilization survey 2003. Dongen: GfK Panel Services Benelux.

42. Statistics Netherlands. (2002). Permanent life situation survey. Den Haag: Statistics Netherlands.

43. Stel, V. S., Smit, J. H., Pluijm, S. M., Visser, M., Deeg, D. J., \& Lips, P. (2004). Comparison of the LASA physical activity questionnaire with a 7-day diary and pedometer. Journal of Clinical Epidemiology, 57(3), 252-258.

44. Dijkers, M., Cicerone, K., Heinemann, A., Brown, M., \& Whiteneck, G. (2009). Poster 89: PART-S: A new measure of satisfaction with participation. Archives of Physical Medicine and Rehabilitation, 90(10), e39.

45. United Nations Educational, Scientific and Cultural Organization. (2006). ISCED 1997. International Standard Classification of Education. UNESCO-UIS.

46. Mangione, C. M., Lee, P. P., Gutierrez, P. R., Spritzer, K., Berry, S., \& Hays, R. D. (2001). Development of the 25-item national eye institute visual function questionnaire. Archives of Ophthalmology, 119(7), 1050-1058.

47. Smets, E. M., Garssen, B., Bonke, B., \& De Haes, J. C. (1995). The multidimensional fatigue inventory (MFI) psychometric qualities of an instrument to assess fatigue. Journal of Psychosomatic Research, 39(3), 315-325.

48. Lemmink, K., \& Bult, P. (1997). The Groningen fitness test for the elderly: GFE: Background, manual and norm scores. Haarlem: De Vrieseborch.

49. Van Sonderen, E. (1993). Measuring social support with the social support list-interactions (SSL-I) and social support listdiscrepancies (SSL-D). A manual. Groningen: Noordelijk Centrum voor Gezondheidsvraagstukken.

50. Hays, R. D., Sherbourne, C. D., \& Mazel, R. M. (1993). The RAND 36-item health survey. Health Economics, 2(3), 217-227.

51. Van der Zee, K. I., \& Sanderman, R. (1993). Measuring general health status with the RAND-36. A manual. Groningen: Noordelijk Centrum voor Gezondheidsvraagstukken.

52. Evers, A. W. M., Kraaimaat, F. W., Van Lankveld, W., Jongen, P. J. H., Jacobs, J. W. G., \& Bijlsma, J. W. J. (2001). Beyond unfavorable thinking: The illness cognition questionnaire for chronic diseases. Journal of Consulting and Clinical Psychology, 69(6), 1026-1036.

53. Schuurmans, H., Steverink, N., Frieswijk, N., Buunk, B. P., Slaets, J. P., \& Lindenberg, S. (2005). How to measure selfmanagement abilities in older people by self-report. The development of the SMAS-30. Quality of Life Research, 14(10), 2215-2228.

54. Field, A. (2009). Discovering statistics using SPSS (3rd ed.). London: Sage Publications Ltd.

55. Kleinbaum, D. G., Kupper, L. L., Nizam, A., \& Muller, K. E. (2008). Applied regression analysis and other multivariable methods (4th ed.). Belmont: Thomson Brooks/Cole.

56. Boerner, K., Reinhardt, J. P., Raykov, T., \& Horowitz, A. (2004). Stability and change in social negativity in later life: Reducing received while maintaining initiated negativity. Journals of Gerontology. Series B, Psychological Sciences and Social Sciences, 59(4), S230-S237.

57. Lindo, G., \& Nordholm, L. (1999). Adaptation strategies, wellbeing and activities of daily living among people with low vision. Journal of Visual Impairment and Blindness, 93(7), 434-446.

58. Heinemann, A. W., Tulsky, D., Dijkers, M., Brown, M., Magasi, S., Gordon, W., et al. (2010). Issues in participation measurement in research and clinical applications. Archives of Physical Medicine and Rehabilitation, 91(9), S72-S76.

59. Perenboom, R. J., \& Chorus, A. M. (2003). Measuring participation according to the international classification of functioning, disability and health (ICF). Disability and Rehabilitation, 25(11-12), 577-587.

60. Dijkers, M. P. (2010). Issues in the conceptualization and measurement of participation: An overview. Archives of Physical Medicine and Rehabilitation, 91(9), S5-S16.

61. Whiteneck, G., \& Dijkers, M. P. (2009). Difficult to measure constructs: Conceptual and methodological issues concerning participation and environmental factors. Archives of Physical Medicine and Rehabilitation, 90(11), S22-S35.

62. Dijkers, M.P., Whiteneck, G., \& El-Jaroudi, R. (2000). Measures of social outcomes in disability research. Archives of Physical Medicine and Rehabilitation, 81(12). S63-S80. 